Article

\title{
Does Consumption of Organic Foods Contribute to Korean Consumers' Subjective Well-Being?
}

\author{
Hyun-Joo Lee $\mathbb{D}$ \\ Department of Consumer Science, Inha University, Incheon 22212, Korea; hyunjoo.lee@inha.ac.kr; \\ Tel.: +82-32-860-8118
}

Received: 20 September 2019; Accepted: 1 October 2019; Published: 4 October 2019

\begin{abstract}
The current study used the value-attitude-behavior hierarchical framework as a theoretical foundation to investigate how consumers' personal values and attitudes influence organic food consumption intention and behavior and how organic food consumption contributes to their perceived subjective well-being. The responses from a total of 420 Korean consumers were analyzed using structural equation modeling. Results of this study indicated that universalism was positively related to attitudes toward environmental and psychological consequences of organic food consumption, whereas benevolence was positively related to attitudes toward health-related consequences. Further, intentions to consume organic foods were positively influenced by attitudes toward health-related and psychological consequences from consuming organic foods, and a positive, significant relation between the intention and the behavior regarding organic food consumption was revealed. Lastly, it was found that organic food consumption significantly affected consumers' physical, psychological, and social well-being perceptions. Research contributions were discussed, and managerial implications were offered in the conclusions.
\end{abstract}

Keywords: organic food consumption; self-transcendence values; subjective well-being; valueattitude-behavior hierarchy; Korean consumers

\section{Introduction}

As people's standard of living in Korea has improved due to increased economic and educational levels, consumers show a growing interest in being healthy and living well. To improve their well-being, people work out regularly, enjoy their leisure time, or try to eat healthy foods [1,2]. Korean people's high interest in well-being has recently expanded to new consumer trends such as 'YOLO' (you live once only), 'Sohwakhaeng' (small but certain happiness), and 'Wolabal' (work and life balance). Nevertheless, according to the Organization for Economic Cooperation and Development (OECD), Korean people's subjective well-being index is the lowest among OECD member countries, mainly due to the longest working hours, highly competitive education system, and low women's labor force participation [3]. Consumption plays a key role in people's lives and their well-being [4]. Various types of behaviors pursuing well-being are associated with consumption, a phenomenon known as well-being-oriented consumer behavior [5,6]. For example, well-being-oriented consumer behavior can include relaxing through yoga and meditation; using spas and beauty facilities; purchasing functional foods and environment-friendly agricultural products; consuming products related to leisure activities, entertainment, and hobbies; and so on [5]. In the US and Europe, some consumers have adopted lifestyles of health and sustainability (LOHAS) as well-being-oriented consumer behavior [7]. In Korea, on the other hand, a lifestyle pursuing healthy lives of individuals and their families is emphasized more than pursuing sustainability [5].

Despite the global economic downturn, well-being trends have led to a rise in consumer demand for organic foods. The organic food market has seen a steady increase in sales over the years in 
Korea. According to the Korea Rural Economic Institute, domestic organic produce sales have been growing at an average of $3.7 \%$ for the past 10 years (2007-2016) and are estimated to reach KRW 594.8 billion in 2025 [8]. In addition, the organic produce market made up $25.9 \%$ of the total eco-friendly produce market in 2016, in comparison to $7.8 \%$ in 2007 [8,9]. In Korea, eco-friendly produce is classified as organic and non-pesticide produce, and eco-friendly produce sales are estimated to represent approximately $20 \%$ of the total produce sales by 2020 [9]. The organic food market in Korea is no longer a niche market, and organic foods are distributed through different types of retailers, such as specialty stores, supermarkets, department stores, and even online retailers [10].

Although some previous studies have examined Korean consumers' consumption behavior of organic foods, few previous researchers have used theoretical frameworks to investigate the big picture, such as exploring organic food consumption behavior along with its motivations and consequences. In addition, although organic food consumption has been widely recognized as well-being-oriented consumer behavior $[9,11]$, little research has empirically explored how consumers' behavior of organic food consumption contributes to their subjective well-being. To fill the gap found in existing literature, the current study used the value-attitude-behavior hierarchical framework as a theoretical foundation to investigate how personal values and attitudes influence intentions and behaviors concerning organic food consumption and how organic food consumption contributes to subjective well-being. The results from this study will make a major contribution to research on consumer behavior by demonstrating the important role of consumption behavior in fostering or improving subjective well-being.

\section{Literature Review}

\subsection{Value-Attitude-Behavior Hierarchy}

Recently, the concept of value consumption has emerged as an important concept. This is a phenomenon in which consumers apply their personal values that they consider important, to their consumption behavior. These personal values are known to serve as a principle that guides the selection of attitudes and behaviors [12]. Although the concept of values has been described in various ways in the literature, researchers generally agree that they are "enduring beliefs" or "motivational goals" relating to "desired modes of conduct or end-states of existence" [13]. Most consumer studies acknowledge the influential role of values in human behavior. Researchers can learn how consumers are related to their choice of a particular brand or product through an understanding of their values. Such an understanding cannot be derived from demographic and lifestyle information [14]. In Pitts et al.'s [15] study, consumers' purchase intention to a particular brand or product increases when they are exposed to an advertisement which is consistent with their personal values. According to Homer and Kahle [16], personal values are the most abstract concept of social cognition, reflecting the most basic characteristics of social adaptation, and thus such an abstract concept of personal values is regarded as the prototype from which attitudes and behaviors are framed. Extending the general notion that personal values predict human attitudes and behaviors, Kahle [17] suggests that personal values indirectly affect human behavior through attitudes that are abstractions of intermediate levels. In other words, the value of the abstract concept is linked to the concrete action through the attitude which is a mediating variable, and this successive event is called the value-attitude-behavior hierarchy [16].

\subsection{Subjective Well-being}

Although researchers have no clear consensus on the definition of well-being, most agree that well-being encompasses several domains of human functioning, relating to issues of mental health, life satisfaction, and social functioning as well as practical aspects of quality of life [18-20]. Well-being has been studied based on two perspectives: the hedonic approach and the eudaimonic approach. In the hedonic approach, which focuses on happiness, important aspects of well-being are the attainment of pleasure and the avoidance of pain [21]. On the other hand, the eudaimonic approach focuses on meaning and self-realization and defines well-being in terms of whether individuals are fully 
functioning [22]. Well-being viewed from the hedonic approach can be called subjective well-being, which is related to a person's own assessment of his or her well-being; it is a person's assessment of his or her environmental situation and behavioral response, and subjective outcomes of a person's well-being assessment process [23]. Diener [24] has actively studied subjective well-being, which is known to be made up of three factors including happiness, life satisfaction, and positive affect [24-26]. Research on well-being from the eudaimonic approach emphasizes 'meaning in life' by concentrating on the recognition of meaning and purpose in life [27]. Ryff [28] defines well-being based on the eudaimonic approach, and it is referred to as psychological well-being. Psychological well-being includes six factors: self-acceptance, positive relations with others, autonomy, environmental mastery, purpose in life, and personal growth. In addition, the concept of social well-being, which describes how an individual performs social functions well, is added to psychological well-being [29], while spiritual well-being can be viewed as one of the dimensions of well-being [30].

Many researchers have tried to identify the factors that influence well-being. The factors can be categorized into genetic factors (e.g., genes, personality traits), circumstantial factors (e.g., income, marital status, employment), and positive behaviors and cognitions [31]. Although existing literature acknowledges positive behaviors as a factor that predicts well-being [31], excessive consumption behaviors can be harmful for well-being [32]. On a different note, Ganglmair-Wooliscroft and Wooliscroft [4] argued that well-being can be either outcomes of consumption or a determinant of consumption behaviors. These disparate assertions deserve further investigation.

\subsection{Conceptual Model and Research Hypotheses}

As shown in Figure 1, the conceptual model of this study is grounded in the value-attitude-behavior hierarchy model suggested by Homer and Kahle [16]. In the left portion of the model, the study intends to examine how personal values influence attitudes toward the consequences of organic food consumption. In particular, the current study focuses on Schwartz's [33] self-transcendence values, which have proven to exert a strong influence on environmentally friendly consumption, responsible consumption, or sustainable consumption [34-37]. Krystallis, Vassallo, Chryssohoidis, and Perrea [35] have shown that self-transcendence values (i.e., universalism and benevolence) are more closely related to organic food consumption than are other values such as hedonism, stimulation, or security.

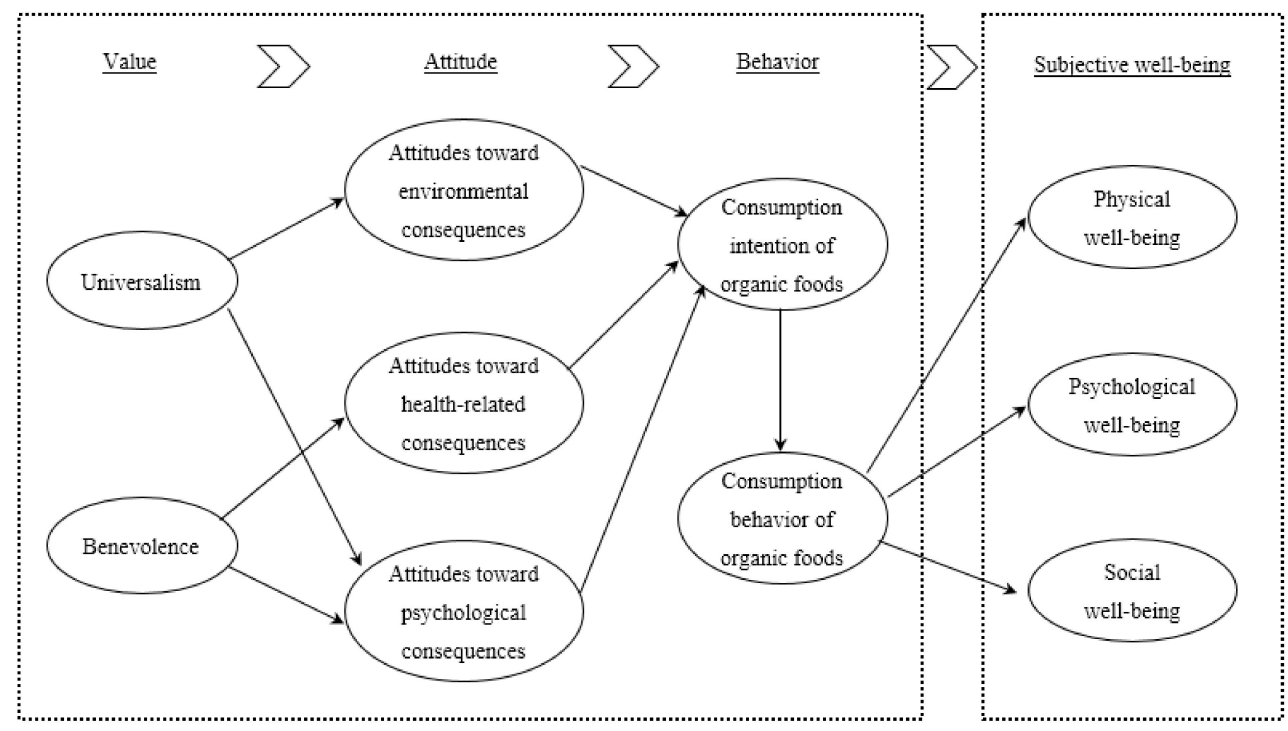

Figure 1. Conceptual model.

Self-transcendence values emphasize accepting others equally and considering the welfare of others important. Self-transcendence values comprise two subdimensions: universalism and benevolence [33]. Universalism emphasizes understanding, appreciation, tolerance, and protection for 
the welfare of mankind and nature, whereas benevolence emphasizes the welfare of those with whom one has a close relationship in everyday life. Therefore, based on the definitions of universalism and benevolence, it is reasonable to suggest that there would be a positive relationship between universalism and attitudes toward environmental consequences of organic food consumption and there would be a positive relationship between benevolence and attitudes toward health-related consequences of organic food consumption. On the other hand, attitudes toward psychological consequences of organic food consumption would be positively affected by both universalism and benevolence. Consumers who consider universalism or benevolence as important would feel pleasure or gratification when they consume organic foods, because the personal value they seek to attain is in line with their consumption behavior. Therefore, the following hypotheses are proposed:

Hypothesis 1 (H1). As consumers consider universalism more important, the consumers develop more positive attitudes toward (a) environmental and (b) psychological consequences of organic food consumption.

Hypothesis 2 (H2). As consumers consider benevolence more important, the consumers develop more positive attitudes toward (a) health-related and (b) psychological consequences of organic food consumption.

In the middle portion of the model, the study aims to investigate the effects of attitudes toward the consequences of organic food consumption on intentions to consume organic foods. In existing literature, attitudes toward organic foods or organic food consumption have been measured based on beliefs, perceptions, and concerns about the attributes of organic foods [38-40], and so, in this study, consumers' perceptions of the consequences of organic food consumption, rather than overall and general attitudes toward organic food consumption, are conceptualized as attitudes in the value-attitude-behavior hierarchy model. Furthermore, attitudes toward the consequences of organic food consumption are examined multidimensionally: environmental, health-related, and psychological consequences. Attitudes toward environmental and health-related consequences are cognitive components, whereas attitudes toward psychological consequences are affective components. In previous studies, attitudes toward organic foods have been studied a lot, but there are not many studies examining attitudes in a multidimensional perspective. Further, a large number of studies have examined attitudes toward organic foods by focusing on health and the environment, but few studies have investigated attitudes toward organic foods from a psychological or emotional point of view. Therefore, this study aims to obtain more concrete results by classifying attitudes toward the consequences of organic food consumption into multi-faceted factors [41-43]. In this study, attitudes toward environmental consequences of organic food consumption refer to a person's cognitive evaluations toward environmental consequences (e.g., environmental improvement or reduction of environmental pollution) resulting from organic food consumption, and attitudes toward health-related consequences of organic food consumption refer to a person's cognitive evaluations toward consequences relating to health aspects (e.g., health improvement) arising from organic food consumption. Attitudes toward psychological consequences refer to a person's positive feelings toward consequences resulting from organic food consumption.

In Homer and Kahle's [16] value-attitude-behavior hierarchy model, behaviors are determined by attitudes. Nevertheless, in some previous studies, behavioral intention was used instead of behavior [44,45]. It is not easy to measure a person's actual behavior precisely because it may be subject to self-reported bias or his or her recollections may not be accurate [46]. According to Fishbein and Ajzen [47], one of the best predictors of human behavior is intention. In the Theory of Reasoned Action (TRA), intention, which is the cognitive representation of a person's readiness to perform a behavior, is considered a direct antecedent of behavior [48]. Thus, the current study attempts to include both intention and behavior to explore value-attitude-behavior hierarchy.

In Arvola et al.'s [41] study of organic food consumption, attitudes toward buying organic foods were assessed as two separate dimensions: cognitive and affective attitudes. They found greater loadings of items for affective attitudes than for cognitive attitudes and attitudes derived from cognitive 
and affective components had a significant influence on intentions to buy organic apples and pizza. On the other hand, Lee and Yun [42] found that utilitarian attitudes toward organic foods had a stronger effect on intentions to purchase organic foods than do hedonic attitudes toward organic foods. To empirically examine the attitude-behavior relation, the following hypotheses are proposed:

Hypothesis 3 (H3). As consumers develop more positive attitudes toward a) environmental, b) health-related, and (c) psychological consequences of organic food consumption, the consumers have higher intentions to consume organic foods.

Hypothesis 4 (H4). As consumers have higher intentions to consume organic foods, the consumers consume organic foods more often.

Finally, in the right portion of the model, the study is designed to explore the importance of organic food consumption to consumers in fostering or improving their subjective well-being. In the current study, subjective well-being is evaluated in terms of physical, psychological, and social well-being levels. In Zhong and Mitchell's [49] study, consumption of hedonic products (i.e., leisure activities, entertainment, and hobbies) was found to indirectly affect subjective well-being through satisfaction with the life domains associated with that consumption. On the other hand, Goetzke et al. [50] found that well-being influenced consumption choices; a decrease in psychological well-being led to an increase in functional food consumption. However, they failed to find a significant effect of well-being on organic food consumption. Based on these findings, the following hypotheses are proposed:

Hypothesis 5 (H5). As consumers consume organic foods more often, the consumers perceive higher (a) physical, (b) psychological, and (c) social well-being.

\section{Methods}

\subsection{Sample}

Participants were recruited from panel members pre-recruited by a market research firm. Eligible participants for the study were primary grocery shoppers in their households living in the Republic of Korea, aged 19 or older, who had ever purchased organic foods. A self-administered online survey was administered only to participants who met the screening requirements. A total of 420 usable surveys were obtained.

\subsection{Measurements}

All the scales had multiple items and were mostly derived from previous studies (Table 1). Only minor adjustments were made to fit the context of the study. Self-transcendence values (universalism and benevolence) were measured using Schwartz's [33] items on a 6-point Likert scale $(-1=$ opposed to my values, $0=$ not important, $4=$ very important). Attitudes toward environmental and health-related consequences of organic food consumption were measured using the items developed by Magnusson, Arvola, Hursti, Åberg, and Sjödén [43]. Based on the findings from the qualitative studies conducted by Padel and Foster [51] and Fotopoulos et al. [52], the items were constructed to measure attitudes toward psychological consequences from consuming organic foods. The items used by Sweeney et al. [53] were adapted to measure intentions to consume organic foods. The items for the attitudes and intentions were rated on a 5-point Likert-type scale ( $1=$ strongly disagree, $5=$ strongly agree). Consumption behavior of organic foods was measured based on the frequency of consuming three categories of organic foods which were the most frequently purchased categories of organic foods by Korean consumers: (1) dairy products (e.g., milk, cheese, or yogurt), (2) fruit or vegetables, and (3) meat, poultry, fish, or eggs. The consumption frequency for each category of organic foods was rated on a 5-point Likert-type scale ( 1 = never consume, 5 = always consume). To measure subjective well-being, the items for physical, psychological, and social well-being were borrowed from Pontin et al.'s [23] subjective well-being scale. The items were rated on a 5-point Likert-type scale ( 1 = strongly disagree, 5 = strongly agree). 
Table 1. Measurement model: scale items for latent variables.

\begin{tabular}{|c|c|c|c|c|c|}
\hline Construct & Scale Item & $\begin{array}{c}\text { Standardized } \\
\text { Estimate }\end{array}$ & t-Value & $\begin{array}{l}\text { Composite } \\
\text { Reliability }\end{array}$ & $\begin{array}{l}\text { Average Variance } \\
\text { Extracted }\end{array}$ \\
\hline \multirow{4}{*}{ Universalism } & A world at peace (free of war and conflict) & 0.649 & $13.878^{* * *}$ & 0.802 & 0.504 \\
\hline & Unity with nature (fitting into nature) & 0.715 & $15.725^{* * *}$ & & \\
\hline & A world of beauty (beauty of nature and the arts) & 0.698 & $15.229 * * *$ & & \\
\hline & Protecting the environment (preserving nature) & 0.773 & $17.464^{* * *}$ & & \\
\hline \multirow{4}{*}{ Benevolence } & Honest (genuine, sincere) & 0.732 & $16.240^{* * *}$ & 0.813 & 0.522 \\
\hline & Helpful (working for the welfare of others) & 0.687 & $14.922 * * *$ & & \\
\hline & Responsible (dependable, reliable) & 0.764 & $17.203 * * *$ & & \\
\hline & Forgiving (willing to pardon others) & 0.704 & $15.408^{* * *}$ & & \\
\hline \multirow{4}{*}{$\begin{array}{l}\text { Attitudes toward environmental } \\
\text { consequences }\end{array}$} & Reduce the use of artificial fertilizers in agriculture & 0.712 & $15.661 * * *$ & 0.818 & 0.529 \\
\hline & Reduce the eutrophication of lakes and watercourses & 0.713 & $15.685^{* * *}$ & & \\
\hline & Reduce the pollution of the soil & 0.774 & $17.544 * * *$ & & \\
\hline & Reduce the use of herbicides and pesticides in agriculture & 0.709 & $15.571^{* * *}$ & & \\
\hline \multirow{5}{*}{$\begin{array}{l}\text { Attitudes toward health-related } \\
\text { consequences }\end{array}$} & Improve my own or my family's health & 0.750 & $17.364^{* * *}$ & 0.870 & 0.572 \\
\hline & Give myself a good conscience & 0.734 & $16.854^{* * *}$ & & \\
\hline & Avoid risks that may be associated with eating non-organic foods & 0.757 & $17.598^{* * *}$ & & \\
\hline & Give my children better food & 0.775 & $18.190^{* * *}$ & & \\
\hline & Reduce the risk for illness in my family & 0.766 & $17.902^{* * *}$ & & \\
\hline \multirow{3}{*}{$\begin{array}{l}\text { Attitudes toward psychological } \\
\text { consequences }\end{array}$} & Make me feel good & 0.857 & $21.277^{* * *}$ & 0.901 & 0.752 \\
\hline & Help me relax & 0.879 & $22.110^{* * *}$ & & \\
\hline & Give me pleasure & 0.865 & $21.558^{* * *}$ & & \\
\hline \multirow{3}{*}{ Consumption intention of organic foods } & I would consider consuming organic foods in the near future & 0.883 & $22.504 * * *$ & 0.913 & 0.778 \\
\hline & I will consume organic foods in the near future & 0.925 & $24.280 * * *$ & & \\
\hline & There is a strong likelihood that I will consume organic foods in the near future & 0.836 & $20.669^{* * *}$ & & \\
\hline \multirow{2}{*}{ Physical well-being } & Are you happy with your ability to perform daily living activities? & 0.703 & $15.143^{* * *}$ & 0.713 & 0.554 \\
\hline & Are you happy with your ability to work? & 0.713 & $15.426^{* * *}$ & & \\
\hline \multirow{7}{*}{ Psychological well-being } & Do you feel able to enjoy life? & 0.668 & $15.003 * * *$ & 0.894 & 0.548 \\
\hline & Do you feel optimistic about the future? & 0.638 & $14.124^{* * *}$ & & \\
\hline & Do you feel in control of your life? & 0.766 & $18.095^{* * *}$ & & \\
\hline & Do you feel happy with yourself as a person? & 0.846 & $21.024 * * *$ & & \\
\hline & Are you happy with your looks and appearance? & 0.743 & $17.331 * * *$ & & \\
\hline & Do you feel able to live your life the way you want? & 0.785 & $18.752 * * *$ & & \\
\hline & Do you feel able to grow and develop as a person? & 0.716 & $16.444^{* * *}$ & & \\
\hline \multirow{3}{*}{ Social well-being } & Are you happy with your friendships and personal relationships? & 0.831 & $19.611^{* * *}$ & 0.814 & 0.596 \\
\hline & Are you comfortable about the way you relate and connect with others? & 0.817 & $19.149 * * *$ & & \\
\hline & Are you able to ask someone for help with a problem? & 0.656 & $14.226^{* * *}$ & & \\
\hline
\end{tabular}




\section{Data Analysis and Results}

\subsection{Sample Characteristics}

A total of 420 responses were obtained for data analysis. Of these, $59.8 \%$ of respondents were female. The age range was between 19 and 68 years, with a mean age of 39 years. The majority (54.8\%) classified themselves as married. For education level, $49.8 \%$ of respondents had completed a four-year college degree. For income category, the largest percentage of respondents $(20.2 \%)$ had an average monthly income of KRW 4-5 million (equivalent to USD \$3480-4360). Compared to the average demographic characteristics of Koreans [54], the sample contains more females and respondents with higher educational attainments and higher incomes. However, according to the National Council of Green Consumer Network in Korea [55], consumers who regularly buy organic foods tend to be females, have higher incomes, be older, and live in apartments. Thus, the sample seems to be representative of Korean organic food consumers.

\subsection{Assessment of Measurement Model}

The data were analyzed by applying confirmatory factor analysis (CFA) to evaluate the validity of the measurement model. CFA was computed with the maximum likelihood estimation method using AMOS software. The measurement model had a good fit $\left(\chi^{2} / \mathrm{df}=1.535, \mathrm{CFI}=0.961\right.$, IFI $=0.961$, and RMSEA $=0.036)$. Evidence of convergent validity of the constructs was found: All factor loadings were above 0.60 , with the lowest value of 0.64 (significant at $p<0.001$ ); the composite reliability ranged from 0.713 to 0.913 ; and the average variance extracted was between 0.504 and 0.778 (Table 1).

To assess discriminant validity, the average variance extracted (AVE) for each construct was compared with the squared of the correlation between the constructs [56]. However, four construct pairs did not meet this criterion (i.e., AVE estimates per some constructs did not exceed the squared correlations with other constructs), so chi-square difference tests were performed to seek for further evidence of discriminant validity. Chi-square difference tests showed highly significant differences $\left(\Delta \chi^{2}\right.$ [1] ranging from 57.692 to $\left.875.179, p<0.001\right)$ between the unconstrained model in which the correlation was freely estimated and the constrained model in which the correlation was fixed to 1. Thus, the results suggest adequate discriminant validity.

\subsection{Hypothesis Testing}

The structural model was built based on the CFA outcomes. As control variables, two demographic characteristics (i.e., age and income) were included in the model. To test the hypothesized relationships, the standardized path coefficients in the structural model were evaluated. The structural model yielded an acceptable fit $\left(\chi^{2} / \mathrm{df}=1.588, \mathrm{CFI}=0.950, \mathrm{IFI}=0.951\right.$, and $\left.\mathrm{RMSEA}=0.037\right)$. We found strong evidence for the proposed model as indicated by support for nine hypothesized relationships (Table 2).

Table 2. Results of hypothesis testing.

\begin{tabular}{ccc}
\hline Hypothesized Paths & Standardized Estimate & t-Value \\
\hline H1a: Universalism $\rightarrow$ Environmental consequences & 0.441 & $7.634^{* * *}$ \\
H1b: Universalism $\rightarrow$ Psychological consequences & 0.441 & $4.167^{* * *}$ \\
H2a: Benevolence $\rightarrow$ Health-related consequences & 0.442 & $8.042^{* * *}$ \\
H2b: Benevolence $\rightarrow$ Psychological consequences & -0.290 \\
H3a: Environmental consequences $\rightarrow$ Consumption intention & 0.006 & $0.075^{* * *}$ \\
H3b: Health-related consequences $\rightarrow$ Consumption intention & 0.474 & $5.096^{* * *}$ \\
H3c: Psychological consequences $\rightarrow$ Consumption intention & 0.295 & $5.012^{* * *}$ \\
H4: Consumption intention $\rightarrow$ Consumption behavior & 0.409 & $6.805^{* * *}$ \\
H5a: Consumption behavior $\rightarrow$ Physical well-being & 0.271 & $4.074^{* * *}$ \\
H5b: Consumption behavior $\rightarrow$ Psychological well-being & 0.278 & $4.568^{* * *}$ \\
H5c: Consumption behavior $\rightarrow$ Social well-being & 0.239 & $3.901^{* * *}$ \\
\hline
\end{tabular}


H1 was fully supported based on the findings that universalism was positively related to attitudes toward environmental consequences $(\gamma=0.441, p<0.001)$ and psychological consequences $(\gamma=0.441$, $p<0.001)$. As consumers considered universalism more important, the consumers were more likely to believe that organic food consumption was environmentally beneficial and made themselves feel better. H2a was supported by the positive impact of benevolence on attitudes toward health-related consequences $(\gamma=0.442, p<0.001)$. As consumers considered benevolence more important, the consumers were more likely to believe that organic food consumption improved their health. However, the path between benevolence and attitudes toward psychological consequences was not significant $(\gamma=-0.031, p=n . s$.$) , resulting in rejection of \mathrm{H} 2 \mathrm{~b}$.

With regard to the relationship between attitudes toward consequences of organic food consumption and intentions to consume organic foods, H3 was partially supported: Consumption intention of organic foods was positively influenced by attitudes toward health-related consequences ( $\beta=0.474, p<0.001)$ and psychological consequences $(\beta=0.295, p<0.001)$ but not by environmental consequences ( $\beta=0.006, p=n$.s.). Thus, $\mathrm{H} 3 \mathrm{~b}$ and $\mathrm{H} 3 \mathrm{c}$ were supported. As consumers were more likely to believe that organic food consumption improved their health and made themselves feel better, they were more likely to have higher intentions to consume organic foods. In accordance with $\mathrm{H} 4$, consumption intention of organic foods was found to be a significant determinant of consumption behavior of organic foods $(\beta=0.409, p<0.001)$. As consumers were more likely to have higher intentions to consume organic foods, they were more likely to consume organic foods more often.

Full support for $\mathrm{H} 5$ was found: Consumption behavior of organic foods had a significant impact on physical well-being $(\beta=0.271, p<0.001)$, psychological well-being $(\beta=0.278, p<0.001)$, and social well-being $(\beta=0.239, p<0.001)$. As consumers were more likely to consume organic foods more often, they were more likely to perceive higher physical, psychological, and social well-being. For the effects of control variables, the negative effect of age on consumption behavior of organic foods was found $(\gamma=-0.171, p<0.01)$, which means that older consumers were less likely to consume organic foods. However, no significant effect of income was found on organic food consumption behavior $(\gamma=0.072$, $p=n . s$.$) .$

\section{Discussions and Implications}

In this study, the aim was two-fold. First, the study aimed to assess how personal values led to consumption intention and behavior of organic foods through attitudes toward consequences of organic food consumption. Second, the study intended to evaluate the effect of consumption behavior of organic foods on subjective well-being. Results of this study indicated that universalism was positively related to attitudes toward environmental and psychological consequences, whereas benevolence had a positive effect on attitudes toward health-related consequences. Findings from this study also showed that consumption intention of organic foods was positively influenced by attitudes toward health-related and psychological consequences of organic food consumption. In addition, the study results indicated that there was a positive, significant connection between consumption intention and consumption behavior. Lastly, we found that consumption behavior of organic foods had a significant impact on physical, psychological, and social well-being perceptions.

The contribution of this study has been to strengthen the theoretical foundation of existing organic food consumption research. First, this study applied Homer and Kahle's [16] value-attitude-behavior hierarchy model to the context of organic food consumption, and it was found that personal values (i.e., universalism) had an indirect effect on intentions and behaviors through attitudes (i.e., attitudes toward health-related and psychological consequences). Second, Homer and Kahle's [16] value-attitude-behavior hierarchy model was extended to include subjective well-being as an outcome variable. The study results demonstrated that organic food consumption could increase subjective well-being in terms of physical, psychological, and social aspects. These findings have rarely been validated in organic food studies. Third, what distinguished the current study from previous studies 
is that it explored attitudes and subjective well-being by subdividing them into three dimensions, respectively, so that it could address broader aspects of the relations among the constructs.

This study also offers several managerial implications. The results demonstrated that universalism was closely associated with attitudes toward two consequences (environmental and psychological) of organic food consumption, whereas benevolence had a significant effect on attitudes toward health-related consequences of organic food consumption. Because universalism focuses on the welfare of the mankind and nature, environmental and psychological attitudes toward organic food consumption might be closely related to universalism. On the other hand, benevolence, which focuses on the welfare of those with whom one has a close relationship in everyday life, might turn out to be firmly related to health-related attitudes toward organic food consumption. From this finding, we conclude that Koreans' value system which is more related to positive attitudes toward organic food consumption seems to be universalism rather than benevolence. However, benevolence should not be overlooked because of its significant effect on consumption intention of organic foods through attitudes toward health-related consequences of organic foods. Thus, if organic food producers, manufacturers, or retailers should encourage more consumption of organic foods, they need to target consumers who appreciate self-transcendence values that are important in their lives. It is surprising that consumption intention of organic foods was significantly influenced by attitudes toward health-related and psychological consequences of organic food consumption, but not by attitudes toward environmental consequences of organic food consumption. Although there is little scientific evidence which supports health-related consequences of organic food consumption [57], Korean consumers' intentions to consume organic foods were increased as their attitudes toward health-related consequences of organic food consumption became more positive. On the other hand, Korean consumers did not depend on environmental consequences of organic food consumption for having intentions to consume organic foods. It is probably due to this that it is hard to make sure whether there are environmental consequences from consuming organic foods. In Lee's [58] study, the researcher found that a major motivation of buying organic foods for Korean consumers was for their families' and children's health. Therefore, advertising or promotional messages could emphasize health-related and psychological consequences of organic food consumption to increase Korean consumers' intention and behavior of consumption of organic foods. In addition, Korean government agencies and organizations (e.g., the Korean Ministry of Agriculture, Food and Rural Affairs, Korea Organic Farming Association) need to develop educational, experiential, or promotional programs to ensure that consumers are well-informed about the environmental consequences of organic food consumption. Lastly, consumption behavior of organic foods was found to have a great influence on subjective well-being. Interestingly, three dimensions of subjective well-being, physical, psychological, and social well-being perceptions were positively influenced by organic food consumption. More organic food consumption led to higher psychological and social well-being as well as physical well-being assessment. Thus, advertising or promotional materials should highlight the role of organic food consumption in developing or improving physical, psychological, and social aspects of subjective well-being. For example, it could be effective to feature the image of people who are happy with their family, friends, and neighbors while having healthy foods, such as organic foods. In addition, the Korean government could encourage people to consume more healthy foods (e.g., organic foods) as one of the ways of improving its level of well-being index, through making a variety of organic foods which are not expensive and are certified as organic from a credible institution available in the markets.

\section{Limitations}

Despite the importance of this study, it has limitations which call for future research. The first limitation is that it is not easy to actually apply the findings about the relationship between personal values and organic foods. Unlike demographic characteristics, personal values are difficult to identify without a separate consumer survey. Therefore, despite the fact that the consumer segment with 
favorable attitudes toward organic food consumption is also the segment that values universalism and benevolence, it is difficult to provide practical implications. The second limitation is that only one personal value system, the self-transcendent value, was included in the research model as the personal values related to organic food consumption. Finally, a major limitation of this study is the use of an Internet panel survey. Since the samples obtained using an Internet panel survey are not obtained by a probability sampling method, it is difficult to generalize the results of the study to all consumers who consume organic foods, so the study results should be interpreted with caution.

Funding: This research received no external funding.

Conflicts of Interest: The authors declare no conflict of interest.

\section{References}

1. Epatko, L. In South Korea, the importance of 'wellbeing'. 2011. Available online: https://www.pbs.org/ newshour/world/korea-wellbeing (accessed on 15 March 2019).

2. Shin, C.-H.; Han, J.-Y. Wellbeing and wellbeing industry. J. Leisure Stud. 2004, 2, 1-17. (In Korean)

3. Yoon, J.-Y. Korea ranks low in quality of life index. 2016. Available online: http://www.koreatimes.co.kr/ www/biz/2018/09/488_206303.html (accessed on 10 April 2019).

4. Ganglmair-Wooliscroft, A.; Wooliscroft, B. Well-being and everyday ethical consumption. J. Happiness Stud. 2017, 20, 141-163. [CrossRef]

5. Kim, M.-J.; Kim, B.-S. The development of the scale of 'well-being' and the determinants of the well-being oriented behavior. J. Cosumption Cul. 2005, 8, 149-164. (In Korean)

6. Jeon, H.-R.; Jae, M.-K. Consumer consciousness toward well-being and well-being oriented consumer behaviors according to the dietary life-Focused on purchasing, using, and disposal behavior of married women. Korean J. Hum. Ecol. 2007, 16, 957-967. [CrossRef]

7. Kim, Y.H. An exploration of well-being-oriented consumers' consciousness toward wustainability: A qualitative research. J. Korean Soc. Food Cul. 2007, 22, 521-527. (In Korean) [CrossRef]

8. Sung, J.; Lee, H. Production status and market prospect of eco-frinedly agricultural products at home and abroad. KREI Agr. Policy Focus 2017, 39, 1-18.

9. Kim, C.; Jeong, H.; Moon, D. Current production status and market prospect of eco-frinedly agricultural products at home and abroad. KREI Agr. Policy Focus 2009, 58, 1-26. (In Korean)

10. Kruse, A. Asian markets show high growth. 2016. Available online: https://myfreelanceprojects.files. wordpress.com/2016/07/korea-organic-market.pdf (accessed on 30 May 2019).

11. Yoo, H.-J. Consumer consciousness toward well-being trend and well-being behaviors. Korean J. Hum. Ecol. 2006, 15, 216-274. (In Korean)

12. Schwartz, S.H.; Bilsky, W. Toward a theory of the universal content and structure of values: extensions and cross-cultural replications. J. Pers. Soc. Psychol. 1990, 58, 878. [CrossRef]

13. Rokeach, M. The Nature of Human Values; Free Press: New York, NY, USA, 1973.

14. Kahle, L.R.; Xie, G.-X. Social values in consumer psychology. In Handbook of Consumer Psychology; Haugtvedt, C.P., Herr, P.M., Kardes, F.R., Eds.; Erlbaum: Mahwah, NJ, USA, 2008; pp. 575-585.

15. Pitts, R.E.; Canty, A.L.; Tsalikis, J. Exploring the impact of personal values on socially oriented communications. Psychol. Market. 1985, 2, 267-278. [CrossRef]

16. Homer, P.M.; Kahle, L.R. A structural equation test of the value-attitude-behavior hierarchy. J. Pers. Soc. Psychol. 1988, 54, 638-646. [CrossRef]

17. Kahle, L.R. Stimulus condition self-selection by males in the interaction of locus of control and skill-chance situations. J. Person. Soc. Psychol. 1980, 38, 50-56. [CrossRef]

18. Kahneman, D.; Krueger, A.B. Developments in the measurement of subjective well-being. J. Econ. Persp. 2006, 20, 3-24. [CrossRef]

19. Kashdan, T.B. The assessment of subjective well-being (issues raised by the Oxford Happiness Questionnaire). Pers. Indiv. Differ. 2004, 36, 1225-1232. [CrossRef]

20. Ryff, C.D.; Keyes, C.L.M. The structure of psychological well-being revisited. J. Personal. Soc. Psychol. 1995, 69, 719. [CrossRef] 
21. Kahneman, D.; Diener, E.; Schwarz, N. Well-Being: Foundations of Hedonic Psychology; Russell Sage Foundation: New York, NY, USA, 1999.

22. Ryan, R.M.; Deci, E.L. On happiness and human potentials: a review of research on hedonic and eudaimonic well-being. Annu. Rev. Psychol. 2001, 52, 141-166. [CrossRef]

23. Pontin, E.; Schwannauer, M.; Tai, S.; Kinderman, P. A UK validation of a general measure of subjective well-being: the modified BBC subjective well-being scale (BBC-SWB). Health. Qual. Life Outcomes 2013, 11, 150. [CrossRef]

24. Diener, E. Subjective well-being. Psychol. Bull. 1984, 95, 542. [CrossRef]

25. Andrews, F.M.; Withey, S.B. Social Indicators of Well-Being: Americans' Perceptions of Life Quality; Plenum: New York, NY, USA, 1976.

26. Diener, E.; Oishi, S.; Lucas, R.E. Personality, culture, and subjective well-being: Emotional and cognitive evaluations of life. Annu. Rev. Psychol. 2003, 54, 403-425. [CrossRef]

27. Graham, C.; Nikolova, M. Bentham or Aristotle in the Development Process? An Empirical Investigation of Capabilities and Subjective Well-Being. World Develop. 2015, 68, 163-179. [CrossRef]

28. Ryff, C.D. Happiness is Everything, or is It? Explorations on the Meaning of Psychological Well-Being. J. Personal. Soc. Psychol. 1989, 57, 1069-1081. [CrossRef]

29. Keyes, C.L.M. Social well-being. Soc. Psychol. Quart. 1998, 61, 121-140. [CrossRef]

30. Van Dierendonck, D. The construct validity of Ryff's scales of psychological well-being and its extension with spiritual well-being. Pers. Indiv. Differ. 2005, 36, 629-643. [CrossRef]

31. Lyubomirsky, S.; King, L.; Diener, E. The benefits of frequent positive affect: does happiness lead to success? Psychol. Bull. 2005, 131, 803. [CrossRef]

32. Sirgy, M.J.; Gurel-Atay, E.; Webb, D.; Cicic, M.; Husic-Mehmedovic, M.; Ekici, A.; Herrmann, A.; Hegazy, I.; Lee, D.-J.; Johar, J. Is materialism all that bad? Effects on satisfaction with material life, life satisfaction, and economic motivation. Soc. Indic. Res. 2013, 110, 349-366. [CrossRef]

33. Schwartz, S.H. Universals in the Content and Structure of Values: theoretical Advances and Empirical Tests in 20 Countries. Advan. Exp. Soc. Psychol. 1992, 25, 1-65. [CrossRef]

34. Dreezens, E.; Martijn, C.; Tenbült, P.; Kok, G.; de Vries, N.K. Food and values: an examination of values underlying attitudes toward genetically modified- and organically grown food products. Appetite 2005, 44, 115-122. [CrossRef]

35. Krystallis, A.; Vassallo, M.; Chryssohoidis, G.; Perrea, T. Societal and individualistic drivers as predictors of organic purchasing revealed through a portrait value questionnaire (PVQ)-based inventory. J. Consum. Behav. 2008, 7, 164-187. [CrossRef]

36. Lea, E.; Worsley, T. Australians' organic food beliefs, demographics and values. Br. Food J. 2005, 107, 855-869. [CrossRef]

37. Thøgersen, J.; Ölander, F. Human values and the emergence of a sustainable consumption pattern: a panel study. J. Econ. Psych. 2002, 23, 605-630. [CrossRef]

38. Chen, M.-F. Attitude toward organic food among Taiwanese as related to health consciousness, environmental attitudes, and the mediating effects of a healthy lifestyle. Br. Food J. 2009, 111, 165-178. [CrossRef]

39. Roddy, G.; Cowan, C.A.; Hutchinson, G. Consumer attitudes and behavior to organic foods in Ireland. J. Int. Consum. Market. 1996, 9, 41-63. [CrossRef]

40. Tsakiridou, E.; Boutsouki, C.; Zotos, Y.; Mattas, K. Attitudes and behaviour towards organic products: an exploratory study. Int. J. Retail Distrib. Manage. 2008, 36, 158-175. [CrossRef]

41. Arvola, A.; Vassallo, M.; Dean, M.; Lampila, P.; Saba, A.; Lähteenmäki, L.; Shepherd, R. Predicting intentions to purchase organic food: the role of affective and moral attitudes in the Theory of Planned Behaviour. Appetite 2008, 50, 443-454. [CrossRef]

42. Lee, H.-J.; Yun, Z.-S. Consumers' perceptions of organic food attributes and cognitive and affective attitudes as determinants of their purchase intentions toward organic food. Food Qual. Preference 2015, 39, $259-267$. [CrossRef]

43. Magnusson, M.K.; Arvola, A.; Hursti, U.-K.K.; Åberg, L.; Sjödén, P.-O. Choice of organic foods is related to perceived consequences for human health and to environmentally friendly behavior. Appetite 2003, 20, 109-117. [CrossRef]

44. Lotz, S.L.; Shim, S.; Gehrt, K.C. A study of Japanese consumers' cognitive hierarchies in formal and informal gift-giving situations. Psychol Market. 2003, 20, 59-85. [CrossRef] 
45. Vaske, J.J.; Donnelly, M.P. A value-attitude-behavior model predicting wildland preservation voting intentions. Soc. Nat. Resour. 1999, 12, 523-537. [CrossRef]

46. Manfredo, M.J.; Shelby, B. The effect of using self-report measures in tests of attitude-behavior relationships. J. Soc. Psychol. 1988, 128, 731-743. [CrossRef]

47. Fishbein, M.; Ajzen, I. Understanding Attitudes and Predicting Social Behavior; Prentice Hall: New Jersey, NJ, USA, 1980.

48. Fishbein, M.; Ajzen, I. Belief, Attitude, Intention And Behavior: An Introduction to Theory and Research; Addison Wesley: Reading, MA, USA, 1975.

49. Zhong, J.Y.; Mitchell, V.-W. A mechanism model of the effect of hedonic product consumption on well-being. J. Consum. Psychol. 2010, 20, 152-162. [CrossRef]

50. Goetzke, B.; Nitzko, S.; Spiller, A. Consumption of organic and functional food. A matter of well-being and health? Appetite 2014, 77, 96-105. [CrossRef]

51. Padel, S.; Foster, C. Exploring the gap between attitudes and behaviour: understanding why consumers buy or do not buy organic food. Br. Food J. 2005, 107, 606-625. [CrossRef]

52. Fotopoulos, C.; Krystallis, A.; Ness, M. Wine produced by organic grapes in Greece: using means-end chains analysis to reveal organic buyers' purchasing motives in comparison to the non-buyers. Food Qual. Preference 2003, 14, 549. [CrossRef]

53. Sweeney, J.C.; Soutar, G.N.; Johnson, L.W. The role of perceived risk in the quality-value relationship: A study in a retail environment. J. Retail. 1999, 75, 77-105. [CrossRef]

54. Jang, Y. The average age of Koreans was 42.1 years old. 2019. Available online: https://www.yna.co.kr/view/ AKR20190118128800004 (accessed on 27 September 2019).

55. Jo, Y.-M. A study on consumer's perception of organic foods and organically processed foods; National Council of Green Consumer Network: Seoul, Korea, 2005. (In Korean)

56. Fornell, C.; Larcker, D.F. Evaluating structural equation models with unobservable variables and measurement error. J. Market Res. 1981, 18, 39-50. [CrossRef]

57. Magkos, F.; Arvaniti, F.; Zampelas, A. Organic food: Buying more safety or just peace of mind? A critical review of the literature. Crc. Crit. Rev. Food Sci. Nutr. 2006, 46, 23-56. [CrossRef]

58. Lee, H.-J. The influence of self-transcendence value on attitudes toward consequences of consuming organic foods and intentions to consume organic foods. J. Consum. Stud. 2017, 28, 115-138. 